\title{
Life dissatisfaction was associated with an increased risk of suicide but adjustment for confounding factors attenuated the association
}

\author{
Koivumaa-Honkanen H, Honkanen R, Viinamäki H, et al. Life satisfaction and suicide: a 20-year follow-up study. AmJ \\ Psychiatry 2001 Mar;158:433-9.
}

QUESTION: Does life satisfaction influence the risk of suicide?

\author{
Design \\ Cohort study with 20 years of follow up.
}

\section{Setting}

Finland.

Source of funding: The Academy of Finland.

For correspondence: Dr $H$

Koivumaa-Honkanen, Department of Psychiatry - 4975, Kuopio University Hospital, PO Box 1777, FIN-70211 Kuopio, Finland. Fax +35817172966 .

\section{Participants}

29137 people who were 18-64 years of age (mean age 34 y, $51 \%$ women) and were alive on $1^{\text {st }}$ May, 1976. Participants were identified using the Finnish Twin Cohort study, and $86 \%$ were twins.

\section{Assessment of risk factors}

Life satisfaction (4 item self report scale [interest in life, happiness, ease of living, feeling of loneliness] with

Associations between life dissatisfaction and increased suicide risk at 20 years

\begin{tabular}{ll} 
Adjustment variables & $\begin{array}{l}\text { Adjusted hazard ratio } \\
(95 \% \mathrm{CI})\end{array}$ \\
Age & $3.0(1.8$ to 5.0$)$ \\
\hline Age, sex & $2.8(1.7$ to 4.6$)$ \\
\hline Age, sex, health & $2.5(1.5$ to 4.2$)$ \\
\hline Age, sex, health, alcohol use & $2.2(1.3$ to 3.7$)$ \\
\hline Age, sex, health, alcohol use, smoking & $2.1(1.3$ to 3.6$)$ \\
\hline Age, sex, health, alcohol use, smoking, physical activity & $1.7(1.0$ to 3.0$)$ \\
\hline Age, sex, health, social class & $2.4(1.5$ to 4.0$)$ \\
\hline Age, sex, health, social class, marital status & $2.3(1.3$ to 3.8$)$ \\
\hline Age, sex, health, social class, marital status, alcohol use, & $1.6(0.9 \text { to } 2.8)^{*}$ \\
\hline smoking, physical activity &
\end{tabular}

scores from 4-20; low scores indicated greater life satisfaction). Potential confounding factors were also assessed: age, sex, health status (presence of illness at baseline), health behaviours (physical activity, smoking, and alcohol consumption), marital status, and social class.

\section{Main outcome measure}

Suicide (National Registry for Cause of Death).

\section{Main results}

182 participants committed suicide during the follow up period (cumulative incidence rates 1.04\% for men and $0.22 \%$ for women). The age adjusted hazard ratio showed an association between life dissatisfaction and an increased risk of suicide (table). A dose response relation existed: the most dissatisfied men (score 19-20 on scale) had a 14.4-fold higher risk of suicide than satisfied men $(p<0.001)$. The overall association between life dissatisfaction and suicide remained when the results were adjusted for various combinations of confounding factors; when the results were adjusted for all potential confounding factors, however, the association was no longer statistically significant (table).

\section{Conclusion}

Life dissatisfaction was associated with an increased risk of suicide, but the association was no longer statistically significant after controlling for age, sex, health status, health behaviours, marital status, and social class.

\section{COMMENTARY}

This prospective cohort study with 20 years follow up, by Koivumaa-Honkanen et al, exemplifies the strong traditions of Scandinavian epidemiological research. It examines the effect on remote suicide risk of self reported life dissatisfaction, modified by other baseline variables. By design most respondents were members of twin pairs, but some singletons (14.5\%) inadvertently included made no difference to the results. As hypothesised, life dissatisfaction predicted later suicide throughout the entire period. Not only did $32 \%$ of people who committed suicide fall in the "dissatisfied" group (18\% of the sample who scored beyond 1 standard deviation from the mean) compared with $18 \%$ of those who did not commit suicide, but also, remarkably, a dose response relation existed between life dissatisfaction and suicide. This relation retained statistical significance as the Cox regression model was progressively adjusted to take into account combinations of the other baseline variables until ultimately all 8 variables were entered, at which point it ceased to be statistically significant. Close examination of the table suggests that it is the inclusion in the equation of physical activity during leisure time that undermines the strength of the proportional hazard ratios. In fact, if this is omitted, the findings are quite robust. This study shows the complexity of the interaction between classes of risk factors. ${ }^{1}$

The structural concept of life satisfaction/dissatisfaction used by the investigators bears examination. They used summed scores on a 4 item self rated scale comprising interest in life, happiness, ease of living, and feeling of loneliness; each item was rated on a 5 point Likert scale. This scale, not unexpectedly, correlated highly $(\mathrm{r}=0.61)$ with self rated scores on the Beck Depression Inventory. In addition to depressed mood, however, its components also signal whether individuals view their quality of life as worthwhile or not, both elements being important precursors in the deadly cognitive sequence that precedes any decision to commit suicide. The authors have thus sampled potentially suicidal ideation at a relatively early stage. These cognitive tendencies were remarkably consistent, being unchanged in a sample of 21000 twins 5 years later.

Suicide is, however, an uncommon phenomenon (182 of 29137 in this study); one cannot envision sufficient sensitivity and specificity to justify routine general use of the life satisfaction scale as an early screen for suicide risk, but it may be useful in the healthcare clinic. 